\title{
Detection of the Human 70-kD and 60-kD Heat Shock Proteins in the Vagina: Relation to Microbial Flora, Vaginal pH, and Method of Contraception
}

\author{
P. Giraldo, ${ }^{1,2 *}$ A. Neuer, ${ }^{1,3}$ A. Ribeiro-Filho, ${ }^{2}$ I. Linhares, ${ }^{4}$ and \\ S.S. Witkin ${ }^{1}$ \\ ${ }^{1}$ Division of Immunology and Infectious Diseases, Department of Obstetrics and Gynecology, Weill \\ Medical College of Cornell University, New York, NY \\ ${ }^{2}$ Department of Gynecology and Obstetrics, University of Campinas, São Paulo, Brazil \\ ${ }^{3}$ Division of Reproductive Endocrinology and Infertility, University of Witten/Herdecke, Germany \\ ${ }^{4}$ Hospital das Clinicas, University of São Paulo, São Paulo, Brazil
}

\begin{abstract}
The expression of the $60-\mathrm{kD}$ and 70-kD heat shock proteins (hsp60 and hsp70) in the vaginas of 43 asymptomatic women of reproductive age with or without a history of recurrent vulvovaginitis (RVV) were compared. Vaginal wash samples were obtained and assayed by enzyme-linked immunosorbent assay (ELISA) for human hsp60 and hsp70. Heat shock protein 70 was not detected in any of the 19 women with no history of $R \mathrm{VV}$, and hsp60 was present in only one woman in this group. In contrast, in the RVV group, 11 (45.8\%) were hsp60-positive and eight $(33.3 \%)$ were hsp70-positive. The presence of either heat shock protein in the vagina was associated with an elevated vaginal $\mathrm{pH}(>4.5)$. Bacterial vaginosis or Candida was identified in some of the asymptomatic subjects; their occurrence was significantly higher in women with vaginal hsp70 than in women with no heat shock proteins. Oral contraceptives were used by $35.7 \%$ of subjects who were negative for vaginal heat shock proteins, as opposed to only $12.5 \%$ of women who were positive for hsp70 and $8.3 \%$ who were positive for hsp60. Expression of heat shock proteins in the vagina may indicate an altered vaginal environment and a susceptibility to vulvovaginal symptoms. Infect. Dis.
\end{abstract} Obstet. Gynecol. 7:23-25, 1999. @ 1999 Wiley-Liss, Inc.

KEY WORDS

heat shock proteins; vaginal flora; vaginal $\mathrm{pH}$; contraception

T wo inducible heat shock proteins (hsps), 70-kD (hsp70) and 60-kD (hsp60), are preferentially synthesized by mammalian cells in response to physiological insults. These proteins foster cell survival under adverse conditions by preventing protein denaturation and incorrect polypeptide folding and aggregation and by tagging denatured proteins for elimination. ${ }^{1}$ In addition, hsp transcription concomitantly downregulates transcription of genes coding for pro-inflammatory cytokines. ${ }^{2}$ Microbial infections may activate host hsp expression by diverse mechanisms: a direct invasion of the host cell by the microorganisms or the consequences of microbe-immune system interactions resulting in the release of inflammatory mediators, microbial products, or toxic free radicals. Similarly, changes in the local milieu, such as an alteration in $\mathrm{pH}$, oxygen, or nutrient concentrations, may also result in hsp expression.

The vagina of healthy women of reproductive

Grant sponsor: Fundação de Amparo a Pesquisa do Estado de São Paulo and the Universidade Estadual de Campinas. *Correspondence to: Dr. Paulo Giraldo, Department of Obstetrics and Gynecology, Weill Medical College of Cornell University, 515 East 71st Street, New York, NY 10021. 
age is not sterile but is normally populated with indigenous bacteria. ${ }^{3}$ 'The predominance of lactobacilli results in an acidic environment, with a vaginal $\mathrm{pH}$ around 4.5. Alterations in vaginal physiology and/or endogenous flora often lead to development of symptoms that, in turn, prompt a woman's visit to a clinician. In most women with vaginitis, the predisposing factors leading to development of symptoms remain unidentified. In this report, we present our results on expression of hsp60 and hsp70 in the vaginas of clinically healthy asymptomatic women of reproductive age and relate the findings to alterations in microbial flora or vaginal $\mathrm{pH}$, as well as to method of contraception.

The study population consisted of 43 nonpregnant women of reproductive age seen at a gynecology clinic in Campinas, Brazil. All subjects were asymptomatic at the time of sample collection and for at least one month previously. Nineteen of the women had an infrequent history of vulvovaginitis (a mean of 0.63 episodes a year) while the remaining 24 women had frequent previous episodes of vulvovaginitis (a mean of 4.3 episodes a year). Vaginal wash samples were obtained by flushing the vagina with $3.0 \mathrm{~mL}$ of sterile saline, using a cotton swab to wash the vaginal walls, and then removing the liquid with a syringe. The samples were centrifuged and the supernatants collected. The supernatants were tested for hsp60 and hsp70 by enzyme-linked immunosorbent assay (ELISA) using monoclonal antibodies specific for mammalian hsp60 and hsp70 bound to wells of a microtiter plate and polyclonal antibodies for detection. ${ }^{4}$ Positive and negative controls were assayed in parallel to the test samples. Vaginal flora were analyzed by wet mount and Gram stain. Bacterial vaginosis was diagnosed by established clinical criteria; the presence of Candida albicans was determined by culture.

Hsp60 was detected in only one $(5.3 \%)$ of the women with infrequent episodes of vulvovaginitis; hsp70 was not detected in any of these women. Among the women with frequent vulvovaginitis, six $(25 \%)$ were positive only for hsp60, three (12.5\%) were positive only for hsp70, and five (20.8\%) had both hsp60 and hsp70. As shown in Table 1 , a vaginal $\mathrm{pH}$ greater than 4.5 was associated with both vaginal hsp60 and hsp70 $(P=0.03)$. Among the 28 women with no vaginal hsps, only three $(10.7 \%)$ had an elevated $\mathrm{pH}$, as opposed to
TABLE I. Relation between vaginal $\mathrm{pH}$ and detection of $\mathrm{Hsp} 60$ and $\mathrm{Hsp} 70$ in the vagina

\begin{tabular}{lcc}
$\begin{array}{l}\text { Heat shock } \\
\text { protein detected }\end{array}$ & No. subjects & $\begin{array}{c}\text { No. with vaginal } \\
\mathrm{pH}>4.5(\%)\end{array}$ \\
\hline Hsp60 & 12 & $5(41.7)^{\mathrm{a}}$ \\
Hsp70 & 8 & $4(50.0)^{\mathrm{a}}$ \\
None & 28 & $3(10.7)$ \\
\hline
\end{tabular}

${ }^{\mathrm{a} P}=0.03$ vs. none.

TABLE 2. Relation between abnormal vaginal flora and detection of $\mathrm{Hsp} 60$ and $\mathrm{Hsp} 70$ in the vagina

\begin{tabular}{lccll}
\hline & & \multicolumn{3}{c}{ No. subjects (\%) } \\
\cline { 3 - 5 } $\begin{array}{l}\text { Heat shock } \\
\text { protein } \\
\text { detected }\end{array}$ & $\begin{array}{c}\text { No. } \\
\text { subjects }\end{array}$ & $\begin{array}{c}\text { Abnormal } \\
\text { flora }\end{array}$ & Candida & $\begin{array}{l}\text { Bacterial } \\
\text { vaginosis }\end{array}$ \\
\hline Hsp60 & 12 & $5(41.7)$ & $2(16.7)$ & $5(41.7)$ \\
Hsp70 & 8 & $5(62.5)^{\mathrm{a}}$ & $3(37.5)^{\mathrm{b}}$ & $5(62.5)^{\mathrm{c}}$ \\
None & 28 & $4(14.2)$ & $2(7.1)$ & $6(21.4)$ \\
\hline
\end{tabular}

${ }^{\mathrm{a}} \mathrm{P}=0.01$ vs. none.

${ }^{\mathrm{b}} \mathrm{P}=0.06$ vs. none

${ }^{c} P=0.04$ vs. none.

TABLE 3. Relation between method of contraception and detection of $\mathrm{Hsp} 60$ and Hsp70 in the vagina

\begin{tabular}{lcccc}
\hline & & \multicolumn{3}{c}{ No. positive (\%) } \\
\cline { 3 - 5 } Method of & No. & Hsp60 & Hsp70 & None \\
contraception & subjects & $\mathrm{n}=12$ & $\mathrm{n}=8$ & $\mathrm{n}=28$ \\
\hline Condom & 15 & $4(33.3)$ & $4(50.0)$ & $7(25.0)$ \\
Pill & 12 & $\mathrm{I}(8.3)$ & $\mathrm{I}(12.5)$ & $10(35.7)$ \\
Vasectomy & 5 & $2(16.7)$ & $\mathrm{I}(12.5)$ & $3(10.7)$ \\
Other & 9 & $3(25.0)$ & $\mathrm{I}(12.5)$ & $5(17.9)$ \\
None & 6 & $2(16.7)$ & $\mathrm{I}(12.5)$ & $3(10.7)$ \\
\hline
\end{tabular}

$41.7 \%$ of women with hsp60 and $50.0 \%$ of those positive for hsp70. Alterations in the vaginal flora were associated with the presence of hsp70 but not hsp60 (Table 2). Among women negative for vaginal hsp, four (14.2\%) had abnormal flora as detected by Gram stain. In marked contrast, $62.5 \%$ of women with vaginal hsp70 had an abnormal Gram stain $(P=0.01)$. The women with vaginal hsp60 had a higher prevalence of abnormal Gram stains than those with no hsps $(5 / 12,41.7 \%)$, but this did not reach statistical significance. Although all women were asymptomatic, bacterial vaginosis or Candida was detected in some women. The prevalence of both was higher in women with vaginal hsp70 $(62.5 \%$ and $37.5 \%$, respectively) than in women with no vaginal hsps $(21.4 \%$ and $7.1 \%, P=$ 
0.06 and 0.04 , respectively). These infections in women with hsp60 did not differ from the controls.

In our study population, use of condoms by the male partner was the method of contraception for 15 of the women, 12 were taking a birth control pill, nine used other methods of birth control, six did not use any contraception, and five had partners who were vasectomized. Although the prevalences of the various methods of contraception were not statistically different in women with or without vaginal hsps, it is interesting to point out that $35.7 \%$ of women without vaginal hsps were using oral contraceptives, as opposed to only $12.5 \%$ of women with hsp70 and $8.3 \%$ with vaginal hsp60 (Table 3).

The results suggest that vaginal expression of hsps, especially hsp70, may be an early indicator of an altered vaginal milieu in asymptomatic women and a predictive marker for subsequent clinical vulvovaginitis. Sensitive methods to identify women at risk for vulvovaginitis and delineation of the most appropriate treatment to prevent subsequent development of symptoms deserves further investigation. Such experiments are in progress. Whether oral contraceptive usage inhibits vaginal hsp expression is an intriguing possibility and is also currently being examined.

\section{REFERENCES}

1. Young RA. Stress proteins in immunology. Annu Rev Immunol 1990;8:401-420.

2. Cahill CM, Waterman WR, Xie Y, Auron PE, Calderwood SK. Transcriptional repression of the prointerleukin $1 \beta$ gene by heat shock factor. J Biol Chem 1996; 271:24874-24879.

3. Bartlett JG, Onderdonk AB, Drude E, et al. Quantitative bacteriology of the vaginal flora. J Infect Dis 1977; 136:271-277.

4. Munoz MG, Jeremias J, Witkin SS. The $60 \mathrm{kDa}$ heat shock protein in human semen: relationship with antibodies to spermatozoa and Chlamydia trachomatis. Hum Reprod 1996;11:2600-2603. 


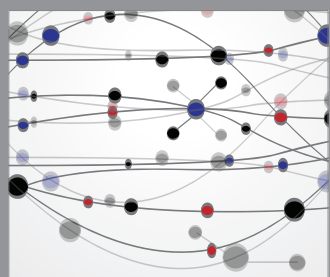

The Scientific World Journal
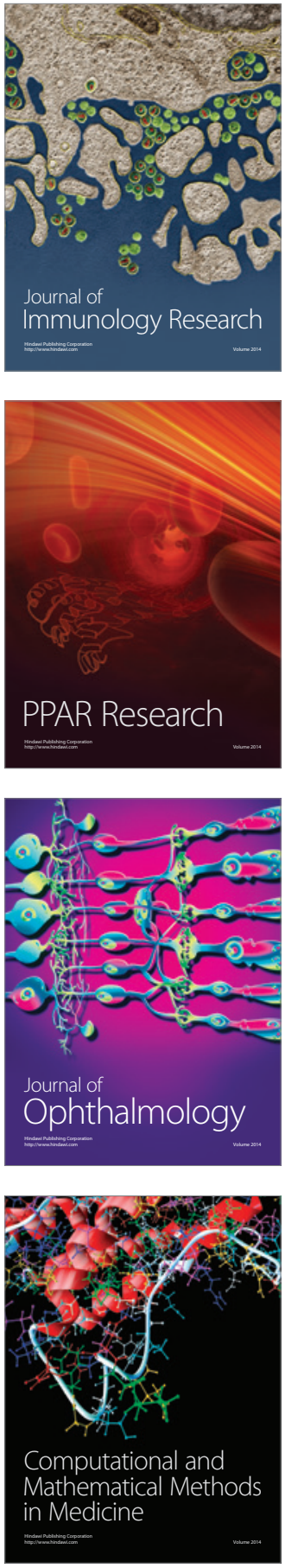

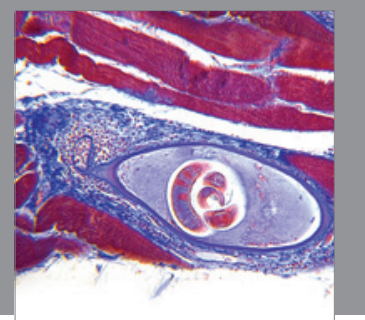

Gastroenterology

Research and Practice
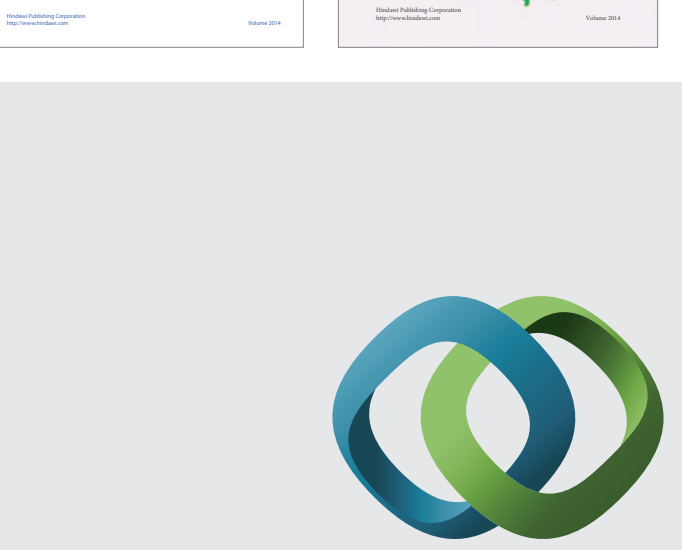

\section{Hindawi}

Submit your manuscripts at

http://www.hindawi.com
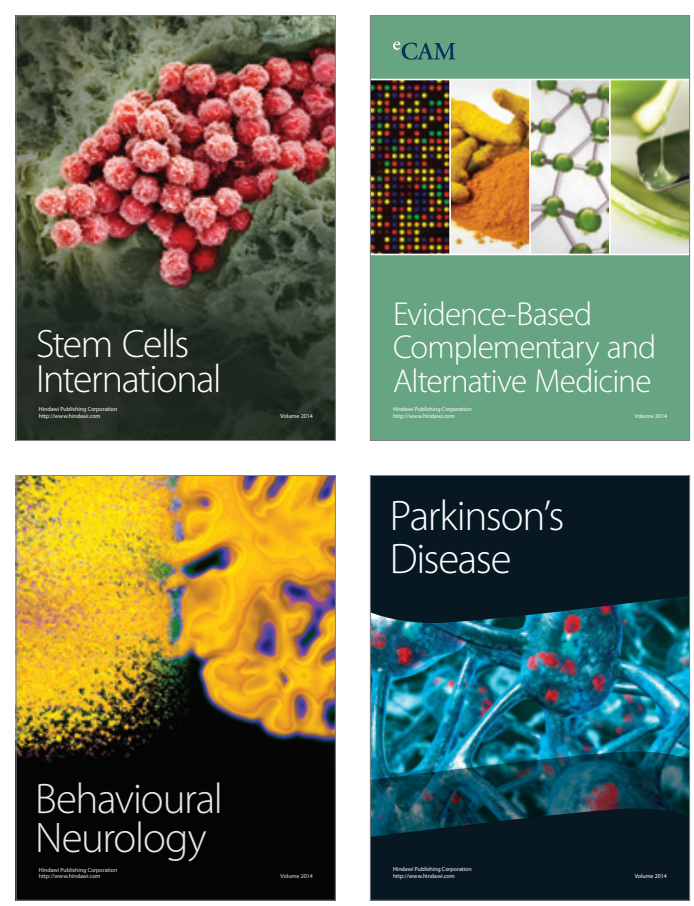

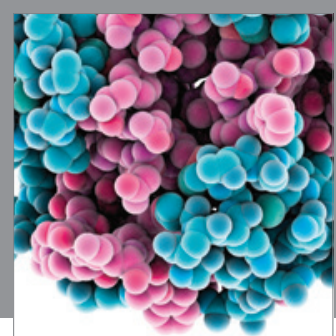

Journal of
Diabetes Research

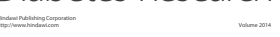

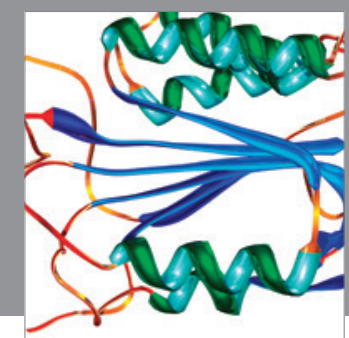

Disease Markers
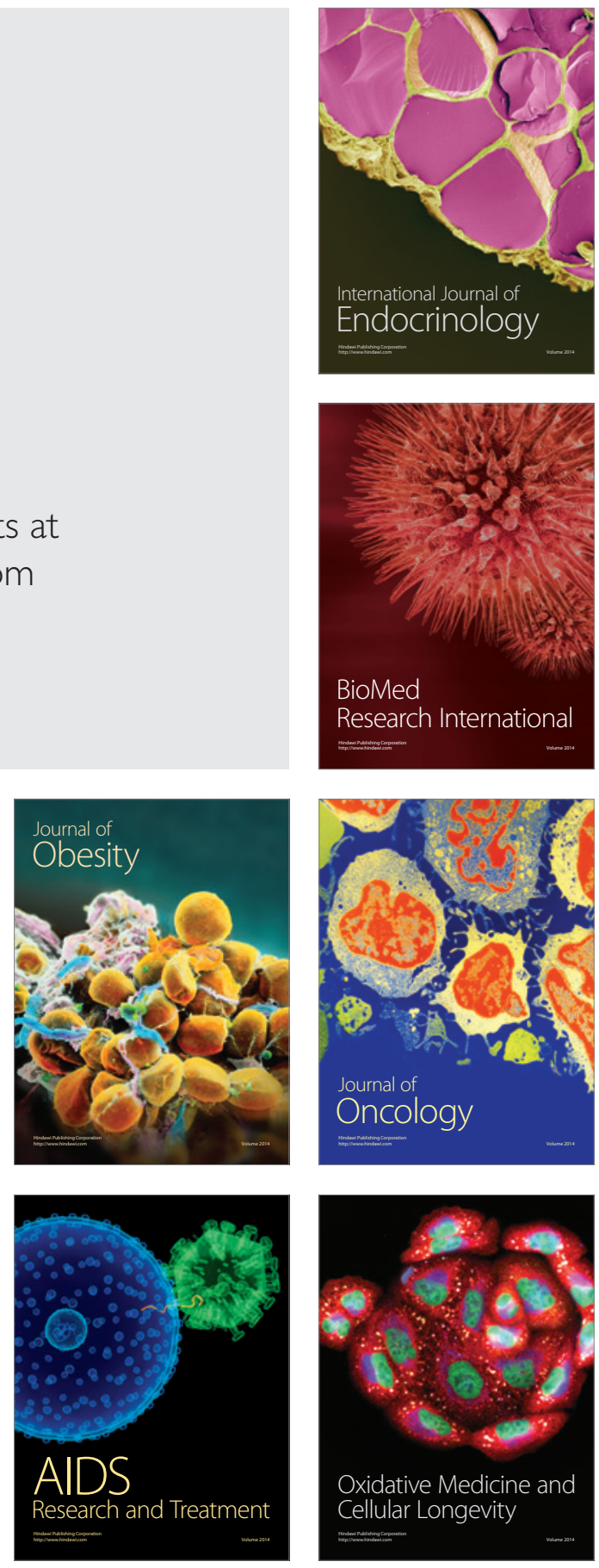